www.nature.com/pj

\title{
Preparation of poly(butylene succinate) copolymers including L-aspartic acid
}

\author{
Akihiro Oishi, Hiroshi Iida and Yoichi Taguchi
}

Copolymers of poly(butylene succinate) (PBS) with amino acids were produced from succinic acid (1), 1,4-butanediol (2) and $1 \mathrm{~mol} \%$ of various amino acids. Their reaction time and molecular weight, as well as thermal and mechanical properties, were studied. The reaction time for polymerization was found to increase as the amount of amino acid was increased, except when L-aspartic acid (3) was used. The preparation of PBS copolymer including 3 was found to be quite different compared with the preparation of copolymer produced using amino acids. The thermal properties of copolymers including 3 are similar to those of the homopolymer without 3 , yet the reaction time, molecular weight distribution and mechanical properties of the copolymers depend significantly on the amount of 3 . The reaction time was found to decrease in proportion to the amount of 3 . If 3 mol\% of 3 is added to the polymerization process, the weight-average molecular weight was found to reach 247000 in only 15 min. The molecular weight distribution $\left(M_{\mathrm{w}} / M_{\mathrm{n}}\right)$ was found to increase and the break strain was found to decrease as the amount of 3 was increased. Similar effects due to the inclusion of 3 were observed in PBS copolymers including $\varepsilon$-caprolactone (4) or 3-octadecyloxy-1,2-propanediol (5).

Polymer Journal (2010) 42, 411-415; doi:10.1038/pj.2010.16; published online 24 March 2010

Keywords: amino acid; copolymer; L-aspartic acid; poly(butylene succinate); polyester; reaction time

\section{INTRODUCTION}

Aliphatic polyesters such as poly(lactic acid) and poly(butylene succinate) (PBS) receive much attention because they are biodegradable polymers that decompose gradually into carbon dioxide and water. Among all polymers, PBS and its copolymers have superior biodegradability in soil and are now commercially available. Although these polymers exhibit good thermal and mechanical properties, more improvement is needed for other applications. The authors have reported the preparation of various PBS copolymers from succinic acid, 1,4-butanediol and various additional compounds such as monoacylglycerol, ${ }^{1}$ 3-alkoxy-1,2-propanediol, ${ }^{2}$ cyclohexanedimethanol ${ }^{3}$ and diglycolic acid, ${ }^{4}$ all of which exhibit good mechanical properties.

In this report, PBS copolymers including various amino acids were synthesized and their properties were studied. Among the amino acids, L-aspartic acid exhibited a different reactivity compared with other amino acids. Addition of $\mathrm{L}$-aspartic acid accelerated the polymerization reaction in contrast to the addition of other $\alpha$-amino acids, which exhibited a delay in polymerization. PBS copolymers, including various amounts of L-aspartic acid, were synthesized and their polymerization time and properties were studied in detail.

\section{EXPERIMENTAL PROCEDURE}

Materials

Succinic acid, 1,4-butanediol, titanium tetraisopropoxide, various $\alpha$-amino acids, $\varepsilon$-caprolactone (Wako Pure Chemical, Osaka, Japan) and 3-ocatadecyloxy-1,2-propanediol (Tokyo Kasei Kogyo, Tokyo, Japan) were used without further purification.

\section{Analysis}

The number-average molecular weight $\left(M_{\mathrm{n}}\right)$, weight-average molecular weight $\left(M_{\mathrm{w}}\right)$ and molecular weight distribution $\left(M_{\mathrm{w}} / M_{\mathrm{n}}\right)$ of polymers were determined by gel permeation chromatography (GPC) at a column oven temperature of $40{ }^{\circ} \mathrm{C}$ in the Tosoh GPC system SC8020 (Tosoh, Tokyo, Japan) equipped with two TSKgel columns (GHMXL-L) (Tosoh) using an RI detector. Molecular weight calibration was performed according to the polystyrene standard. Chloroform was used as the eluent at a flow rate of $1.0 \mathrm{ml} \mathrm{min}^{-1}$. The compositions of the copolymers were analyzed using ${ }^{1} \mathrm{H}$ nuclear magnetic resonance spectra measured with a Varian NOVA400 spectrometer $(400 \mathrm{MHz})$ (Varian, Palo Alto, CA, USA).

The thermal properties of polymers, as well as their glass transition temperature $\left(T_{\mathrm{g}}\right)$, melting temperature $\left(T_{\mathrm{m}}\right)$ and heat of fusion $\left(\Delta H_{\mathrm{m}}\right)$, were examined by differential scanning calorimetry (DSC) using a Seiko DSC-220 apparatus (Seiko Instruments, Chiba, Japan). The polymer samples were scanned from -100 to $200^{\circ} \mathrm{C}$ at a heating rate of $20^{\circ} \mathrm{C}$ per min under a nitrogen stream; $T_{\mathrm{m}}$, $\Delta H_{\mathrm{m}}$ and $T_{\mathrm{g}}$ were determined for second heating. A $2 \%$ thermal decomposition temperature $\left(T_{\mathrm{d} 2}\right)$ was determined by thermogravimetry using a Seiko TG/DTA220 apparatus (Seiko Instruments). 


\section{Tensile test}

Films ( $\sim 0.2 \mathrm{~mm}$ thick) were prepared using the heat-press method at $200 \mathrm{~kg} \mathrm{~cm}^{-2}$, $140^{\circ} \mathrm{C}$. All tensile measurements were performed using a Shimadzu Autograph AGS tester (Shimadzu, Kyoto, Japan) at room temperature. Experiments were carried out at a constant crosshead speed of $10 \mathrm{~mm} \mathrm{~min}^{-1}$. At least three samples were tested under the same conditions for each polymer, and the average value was calculated.

\section{Preparation of copolymers}

The procedure was as follows: a four-necked $100 \mathrm{ml}$ flask was charged with $20.83 \mathrm{~g}(177 \mathrm{mmol})$ succinic acid, $16.85 \mathrm{~g}(187 \mathrm{mmol})$ 1,4-butanediol, $0.53 \mathrm{~g}$ $(3.58 \mathrm{mmol}) \mathrm{L}$-aspartic acid and $25 \mu \mathrm{l}(\sim 0.1 \mathrm{mmol})$ titanium tetraisopropoxide under a dry $\mathrm{N}_{2}$ atmosphere. The flask, with a gas introduction inlet and outlet and connected to a condenser, was first immersed in a silicon bath. The bath was then heated to $230^{\circ} \mathrm{C}$ for $1 \mathrm{~h}$. Water produced by esterification reaction was removed. Subsequently, the condenser was removed and polycondensation was carried out, over a gradually decreasing pressure, for a final vacuum of $<1 \mathrm{~mm} \mathrm{Hg}$. The reaction was ended after $30 \mathrm{~min}$ because the viscosity of the product reached a high enough level to allow the polymer to be twisted around a stirring rod. $M_{\mathrm{n}}, M_{\mathrm{w}}$ and $M_{\mathrm{w}} / M_{\mathrm{n}}$ values of the resulting white solid were determined to be 43300,249400 and 5.76, respectively. $T_{\mathrm{m}}, T_{\mathrm{g}}$ and $T_{\mathrm{d} 2}$ values of the polymer were determined to be $111.7^{\circ} \mathrm{C},-28.8^{\circ} \mathrm{C}$ and $299.1^{\circ} \mathrm{C}$, respectively.

\section{RESULTS AND DISCUSSION}

PBS copolymers, including amide bond formation, were reported to exhibit good thermal properties. ${ }^{5}$ We tried to produce PBS copolymers including amide bond formation of amino acids because the amino acid is simple to obtain from natural products and has two functional groups: the carboxylic group and the amino group. PBS copolymers, including small amounts of amino acids, can be obtained with high molecular weights from the polycondensation reaction of succinic acid (1), 1,4-butanediol (2) and amino acid. However, larger amounts of amino acids decrease the molecular weight significantly.

Table 1 The reaction time and molecular weight of PBS copolymers including amino acids

\begin{tabular}{|c|c|c|c|c|c|c|}
\hline Run & Amino acid & Product & $\begin{array}{l}\text { Reaction } \\
\text { time }(h)\end{array}$ & $\mathrm{M}_{n}$ & $\mathrm{M}_{w}$ & $\mathrm{M}_{w} \mathrm{M}_{n}$ \\
\hline 1 & None & PBS & 3 & 76500 & 142000 & 1.86 \\
\hline 2 & Glycine & PBSGly & 7 & 41800 & 74100 & 1.78 \\
\hline 3 & L-Alanine & PBSAla & 7 & 68400 & 119000 & 1.74 \\
\hline 4 & L-Aspartic acid & PBSAsp & 1.7 & 46500 & 138000 & 2.97 \\
\hline 5 & L-Glutamic acid & PBSGlu & 7 & 37800 & 75700 & 2.01 \\
\hline 6 & L-Phenylalanine & PBSPhe & 7 & 58600 & 103000 & 1.76 \\
\hline
\end{tabular}

Abbreviations: $M_{\mathrm{n}}$, number-average molecular weight; $M_{\mathrm{w}}$, weight-average molecular weight;

$M_{\mathrm{w}} / M_{\mathrm{n}}$, molecular weight distribution; PBS, poly(butylene succinate).

Succinic acid $180 \mathrm{mmol}, 1,4$-butanediol $187 \mathrm{mmol}$ and amino acid $1.8 \mathrm{mmol}$
Table 1 shows the reaction time under high vacuum, number-average molecular weights $\left(M_{\mathrm{n}}\right)$, weight-average molecular weights $\left(M_{\mathrm{w}}\right)$ and molecular weight distribution $\left(M_{\mathrm{w}} / M_{\mathrm{n}}\right)$ of copolymers when $1 \mathrm{~mol} \%$ of various amino acids was used for copolymerization. The reaction time for polymerization was increased with the increase in amino acids, except for L-aspartic acid (3).

Table 2 shows the thermal and mechanical properties of the copolymers. The thermal properties, such as the glass transition temperature $\left(T_{\mathrm{g}}\right)$, melting temperature $\left(T_{\mathrm{m}}\right)$, heat of fusion $\left(\Delta H_{\mathrm{m}}\right)$ and $2 \%$ thermal decomposition temperature $\left(T_{\mathrm{d} 2}\right)$, did not change much in the experiments, and were, in general, in agreement with the properties of the PBS homopolymer. The mechanical properties of copolymers, especially the break strain, were varied and were dependent on the type of amino acid used. Copolymers with alanine exhibited a slightly higher break strain than the PBS homopolymer. In this study, $\mathbf{3}$ was of greater significance because copolymers with 3 exhibited a shorter polycondensation time compared with PBS. PBS and its copolymers generally need a longer reaction time to reach the position of higher molecular weight polymers. Some studies have reported the shortening of polymerization time using chain extension by diisocyanate, ${ }^{6-8}$ the addition of co-catalyst, ${ }^{9,10}$ the addition of threefunctional polyols, ${ }^{11}$ and the use of microwave. ${ }^{12}$

Copolymers of PBS including 3 were prepared (Scheme 1). Table 3 shows the reaction time and molecular weight of PBS copolymers including various amounts of 3 . Their thermal and mechanical properties are shown in Table 4 . When larger amounts of 3 were used to copolymerize, the reaction time was found to decrease. If $3 \mathrm{~mol} \%$ of 3 was used for polymerization, it took only $15 \mathrm{~min}$ to obtain a copolymer with an $M_{\mathrm{w}}$ of 247000 (PBSAsp3). The $M_{\mathrm{w}} / M_{\mathrm{n}}$ value of copolymers was found to increase with an increase in 3 . The $M_{\mathrm{w}} / M_{\mathrm{n}}$ values of PBS, PBSAsp1, PBSAsp2 and PBSAsp3 were determined to be $1.86,2.97,5.76$ and 6.71 , respectively. Although PBS copolymers including $0.3 \mathrm{~mol} \%$ of 3 had almost the same reaction time, molecular weight distribution and thermal properties of the PBS homopolymer, the mechanical properties changed. In particular, the break strain increased from 289 to $548 \%$. However, further increases of 3 decreased the break strain significantly-the break strain of PBSAsp3 was only 14\% (Table 4, run 2).

It was reported that PBS copolymer including $\varepsilon$-caprolactone (4) exhibits superior biodegradability and mechanical properties compared with PBS homopolymer. ${ }^{13}$ Thus, the effect of the addition of aspartic acid to PBS copolymers including $10 \mathrm{~mol}$ and $20 \mathrm{~mol} \%$ of 4 was studied (Scheme 2). Table 5 shows the reaction time and molecular weight of PBS copolymers including 3 and 4 . Similar to the results presented in Table 3, the reaction was completed more rapidly. In addition, the molecular weight distribution, $M_{\mathrm{w}} / M_{\mathrm{n}}$, was found to increase with the increase in 3 .

Table 2 The thermal and mechanical properties of PBS copolymers including amino acids

\begin{tabular}{|c|c|c|c|c|c|c|c|c|c|}
\hline Run & Product & $\begin{array}{l}\mathrm{T}_{g} \\
\left({ }^{\circ} \mathrm{C}\right)\end{array}$ & $\begin{array}{l}\mathrm{T}_{m} \\
\left({ }^{\circ} \mathrm{C}\right)\end{array}$ & $\begin{array}{c}-\Delta \mathrm{H}_{m} \\
\left(m J m g^{-1}\right)\end{array}$ & $\begin{array}{l}\mathrm{T}_{d 2} \\
(\mathrm{C})\end{array}$ & $\begin{array}{l}\text { Elastic } \\
(\mathrm{MPa})\end{array}$ & $\begin{array}{c}\text { Yield stress } \\
\text { (MPa) }\end{array}$ & $\begin{array}{c}\text { Break stress } \\
\text { (MPa) }\end{array}$ & $\begin{array}{c}\text { Break strain } \\
\text { (\%) }\end{array}$ \\
\hline 1 & PBS & -34.2 & 114.9 & 48.2 & 308.1 & 283.8 & 30.2 & 30.8 & 289 \\
\hline 2 & PBSGly & -34.7 & 114.9 & 64.8 & 325.5 & 328.3 & 31.9 & 30.8 & 19 \\
\hline 3 & PBSAla & -30.6 & 114.4 & 56.1 & 328.9 & 278.4 & 27.1 & 33.8 & 381 \\
\hline 4 & PBSAsp & -39 & 109.5 & 55.4 & 311.6 & 280.8 & 27.9 & 26.5 & 38 \\
\hline 5 & PBSGlu & -30.5 & 111.4 & 108 & 339.1 & 200.2 & 27.4 & 28.7 & 272 \\
\hline 6 & PBSPhe & -34.6 & 113.5 & 68.5 & 323.3 & 295 & 28.8 & 28.8 & 271 \\
\hline
\end{tabular}

Abbreviations: $\Delta H_{\mathrm{m}}$, heat of fusion; PBS, poly(butylene succinate); $T_{\mathrm{d} 2}, 2 \%$ thermal decomposition temperature; $T_{\mathrm{g}}$, glass transition temperature; $T_{\mathrm{m}}$, melting temperature. 


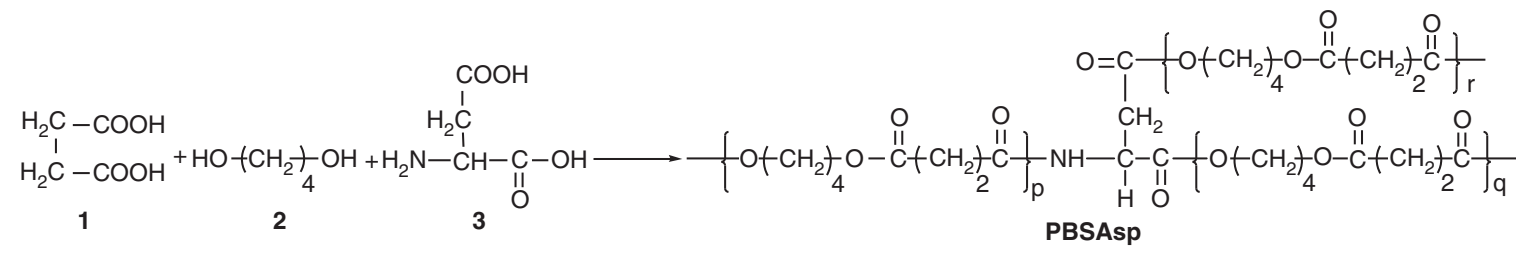

Scheme 1 Polymerization of PBS copolymers including 3.

Table 3 The reaction time and molecular weight of PBS copolymers including aspartic acid

\begin{tabular}{|c|c|c|c|c|c|c|c|c|c|}
\hline 1 & 180 & 188 & 0 & 0 & PBS & $3 \mathrm{~h}$ & 76500 & 142000 & 1.86 \\
\hline 3 & 180 & 189 & 1.78 & 1 & PBSAsp1 & $1.7 \mathrm{~h}$ & 46500 & 138000 & 2.97 \\
\hline 4 & 177 & 187 & 3.58 & 2 & PBSAsp2 & $30 \mathrm{~min}$ & 43300 & 249000 & 5.76 \\
\hline 5 & 175 & 187 & 5.36 & 3 & PBSAsp3 & $15 \mathrm{~min}$ & 36800 & 247000 & 6.71 \\
\hline
\end{tabular}

Abbreviations: $M_{\mathrm{n}}$, number-average molecular weight; $M_{\mathrm{w}}$, weight-average molecular weight; $M_{\mathrm{w}} / M_{\mathrm{n}}$, molecular weight distribution; PBS, poly(butylene succinate); 1, succinic acid; 2, 1,4-butanediol; 3, L-aspartic acid.

Table 4 The thermal and mechanical properties of PBS copolymers including aspartic acid

\begin{tabular}{|c|c|c|c|c|c|c|c|c|c|}
\hline Run & Product & $\begin{array}{l}\mathrm{T}_{g} \\
\left({ }^{\circ} \mathrm{C}\right)\end{array}$ & $\begin{array}{l}\mathrm{T}_{m} \\
\left({ }^{\circ} \mathrm{C}\right)\end{array}$ & $\begin{array}{c}-\Delta \mathrm{H}_{m} \\
\left(m J m g^{-1}\right)\end{array}$ & $\begin{array}{l}\mathrm{T}_{d 2} \\
\left({ }^{\circ} \mathrm{C}\right)\end{array}$ & $\begin{array}{l}\text { Elastic } \\
(\mathrm{MPa})\end{array}$ & $\begin{array}{c}\text { Yield stress } \\
\text { (MPa) }\end{array}$ & $\begin{array}{c}\text { Break stress } \\
\text { (MPa) }\end{array}$ & $\begin{array}{c}\text { Break strain } \\
\text { (\%) }\end{array}$ \\
\hline 1 & PBS & -34.2 & 114.9 & 48.2 & 308.1 & 283.8 & 30.2 & 30.8 & 289 \\
\hline 2 & PBSAsp0.3 & -30.6 & 111.1 & 100 & 323.3 & 248 & 25.1 & 43.4 & 548 \\
\hline 3 & PBSAsp1 & -39 & 109.5 & 55.4 & 311.6 & 280.8 & 27.9 & 26.5 & 38 \\
\hline 4 & PBSAsp2 & -28.8 & 111.7 & 107 & 299.1 & 276.2 & 26.3 & 26.3 & 20 \\
\hline 5 & PBSAsp3 & -28.6 & 108.9 & 108 & 300.3 & 279 & 22.8 & 22.8 & 14 \\
\hline
\end{tabular}

Abbreviations: $\Delta H_{\mathrm{m}}$, heat of fusion; PBS, poly(butylene succinate); $T_{\mathrm{d} 2}, 2 \%$ thermal decomposition temperature; $T_{\mathrm{g}}$, glass transition temperature; $T_{\mathrm{m}}$, melting temperature.

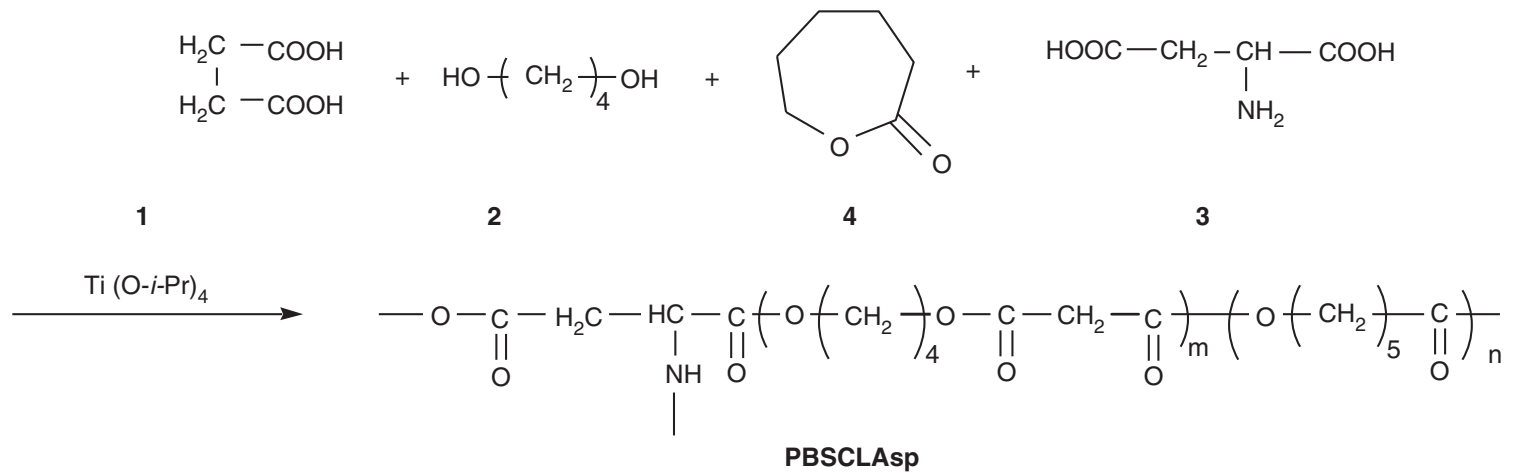

Scheme 2 Polymerization of PBS copolymers including 3 and 4.

Table 6 shows the thermal and mechanical properties of the copolymers. The thermal properties of the copolymers with 3 were not significantly different from those of copolymers without 3 . However, the mechanical properties, especially the break strain, changed significantly, depending on the amount of 3 . These results are similar to the results presented in Table 4.

PBS copolymers including 3-octadecyloxy-1,2-propanediol (5) exhibit a good break strain level and specific biodegradability; however, the reaction time of the polymer is long because $\mathbf{5}$ has a low reactivity. ${ }^{3}$ The addition effect of 3 to the PBS copolymer including 3 and $5 \mathrm{~mol} \%$ of 5 was studied (Scheme 3). Table 7 shows the reaction time and molecular weight of PBS copolymers including 3 and 5. The reaction time was found to decrease in proportion to the amount of 3 . The $M_{\mathrm{w}} / M_{\mathrm{n}}$ value was found to increase with increasing 3 . These results are in agreement with the results of Tables 3 and 5 . 
Table 5 The reaction time and molecular weight of PBS copolymers including $\varepsilon$-caprolactone and aspartic acid

\begin{tabular}{|c|c|c|c|c|c|c|c|c|c|}
\hline Run & $\begin{array}{c}1 \\
(m m o l)\end{array}$ & $\begin{array}{c}2 \\
(m m o l)\end{array}$ & $\begin{array}{c}4 \\
(m m o l)\end{array}$ & $\begin{array}{c}3 \\
(\mathrm{mmol})\end{array}$ & Product & Reaction time & $\mathrm{M}_{n}$ & $M_{w}$ & $\mathrm{M}_{w} \mathrm{M}_{n}$ \\
\hline 1 & 180 & 188 & 0 & 0 & PBS & $3 \mathrm{~h}$ & 76500 & 142000 & 1.86 \\
\hline 3 & 180 & 187 & 18 & 0.9 & PBSCL10Asp0.5 & $1.5 \mathrm{~h}$ & 59300 & 142900 & 2.41 \\
\hline 4 & 180 & 189 & 18 & 1.8 & PBSCL10Asp1 & $1.5 \mathrm{~h}$ & 46800 & 131500 & 2.81 \\
\hline 5 & 180 & 190 & 18 & 5.4 & PBSCL10Asp3 & $20 \mathrm{~min}$ & 38800 & 259200 & 6.68 \\
\hline 8 & 181 & 187 & 36 & 1.8 & PBSCL20Asp1 & $1 \mathrm{~h}$ & 53600 & 187100 & 3.49 \\
\hline 9 & 180 & 187 & 36 & 5.4 & PBSCL20Asp3 & $10 \mathrm{~min}$ & 35300 & 289500 & 8.20 \\
\hline
\end{tabular}

Abbreviations: $M_{\mathrm{n}}$, number-average molecular weight; $M_{\mathrm{w}}$, weight-average molecular weight; $M_{\mathrm{w}} / M_{\mathrm{n}}$, molecular weight distribution; PBS, poly(butylene succinate); 1, succinic acid; 2, 1,4-butanediol; 3, L-aspartic acid; 4, $\varepsilon$-caprolactone.

Table 6 The thermal and mechanical properties of PBS copolymers including \&-caprolactone and aspartic acid

\begin{tabular}{|c|c|c|c|c|c|c|c|c|c|}
\hline Run & Product & $\begin{array}{l}\mathrm{T}_{g} \\
\left({ }^{\circ} \mathrm{C}\right)\end{array}$ & $\begin{array}{l}\mathrm{T}_{m} \\
\left({ }^{\circ} \mathrm{C}\right)\end{array}$ & $\begin{array}{c}-\Delta \mathrm{H}_{m} \\
\left(m J m g^{-1}\right)\end{array}$ & $\begin{array}{l}\mathrm{T}_{d 2} \\
\left({ }^{\circ} \mathrm{C}\right)\end{array}$ & $\begin{array}{l}\text { Elastic } \\
(\mathrm{MPa})\end{array}$ & $\begin{array}{c}\text { Yield stress } \\
\text { (MPa) }\end{array}$ & $\begin{array}{c}\text { Break stress } \\
\text { (MPa) }\end{array}$ & $\begin{array}{c}\text { Break strain } \\
\text { (\%) }\end{array}$ \\
\hline 1 & PBS & -34.2 & 114.9 & 48.2 & 308 & 283.8 & 30.2 & 30.8 & 289 \\
\hline 2 & PBSCL10 & -34.3 & 105.2 & 71.9 & 331.3 & 142.9 & 24.7 & 26.3 & 291 \\
\hline 3 & PBSCL10Asp0.5 & -21.1 & 107.4 & 57.5 & 320.3 & 134.6 & 25 & 23.2 & 257 \\
\hline 4 & PBSCL10Asp1 & -35 & 102.9 & 95.8 & 300.9 & 141.5 & 24.4 & 24.2 & 21 \\
\hline 5 & PBSCL10Asp3 & -32.6 & 101.6 & 75.1 & 300.7 & 133 & 24 & 23.8 & 19 \\
\hline 6 & PBSCL20 & -36.3 & 100.9 & 49.7 & 322 & 116.5 & 20.2 & 47.4 & 1102 \\
\hline 7 & PBSCL20Asp0.5 & -38 & 98 & 59.7 & 321.1 & 100.5 & 18.6 & 20 & 306 \\
\hline 8 & PBSCL20Asp1 & -36 & 98.2 & 79.4 & 302.3 & 115.4 & 19.9 & 19.2 & 196 \\
\hline 9 & PBSCL20Asp3 & -35.7 & 96 & 61.7 & 299.3 & 107.5 & 19.2 & 17.9 & 27 \\
\hline
\end{tabular}

Abbreviations: $\Delta H_{\mathrm{m}}$, heat of fusion; PBS, poly(butylene succinate); $T_{\mathrm{d} 2}, 2 \%$ thermal decomposition temperature; $T_{\mathrm{g}}$, glass transition temperature; $T_{\mathrm{m}}$, melting temperature.

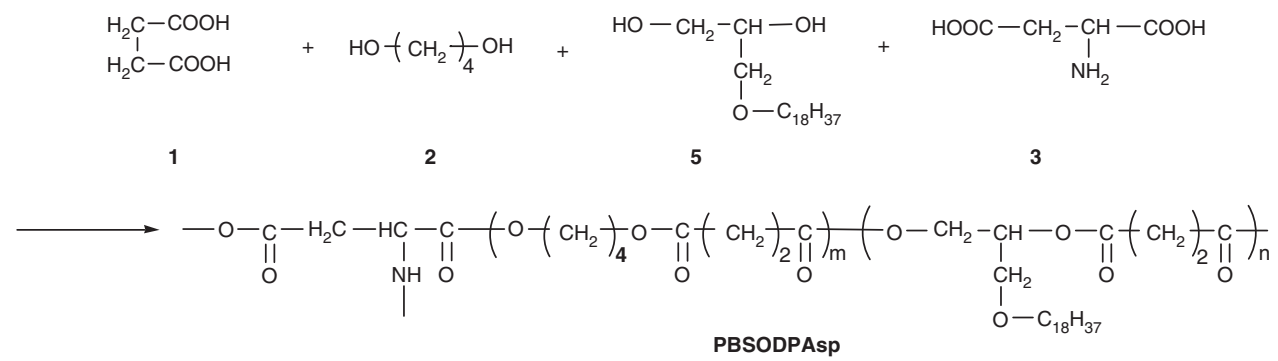

Scheme 3 Polymerization of PBS copolymers including 3 and 5.

Table 8 shows the thermal and mechanical properties of the copolymers, which is consistent with the results presented in Tables 4 and 6 - the break strain was found to decrease with increasing amounts of 3 .

It was found that the addition of $\mathbf{3}$ was effective in accelerating the polymerization of PBS and its various copolymers. It was suggested that this is due to the three functional groups of $\mathbf{3}$, two carboxylic groups and an amino group, producing a network polymer. A similar acceleration effect has been reported for three-functional polyols. ${ }^{11}$ However, L-glutamic acid, which has a structure that is similar to 3, produced the same behavior as other amino acids that had two functional groups. This means that there is another reason for the specific results linked to 3 .

\section{CONCLUSION}

PBS copolymers including $1 \mathrm{~mol} \%$ of amino acid were produced at high molecular weights and good break strain. However, if the amount of amino acid except for $\mathbf{3}$ was increased, a high-molecular-weight copolymer could not be obtained. In contrast, PBS copolymers, including small amounts of 3 , were prepared over a short reaction time with high weight-average molecular weight. The molecular weight distribution of the copolymer was found to increase, whereas the break strain was found to decrease with an increase in 3. PBS copolymers including $\mathbf{4}$ and $\mathbf{5}$ could also be obtained over a shorter time with high $M_{\mathrm{w}}$ and high $M_{\mathrm{w}} / M_{\mathrm{n}}$ with the addition of 3 . These results are considered to be attributed to the three functions of 3 ; an 
Table 7 The reaction time and molecular weight of PBS copolymers including 3-octadecyloxy-1,2-propanediol and aspartic acid

\begin{tabular}{|c|c|c|c|c|c|c|c|c|c|}
\hline Run & $\begin{array}{c}1 \\
(m m o l)\end{array}$ & $\begin{array}{c}2 \\
(m m o l)\end{array}$ & $\begin{array}{c}5 \\
(\mathrm{mmol})\end{array}$ & $\begin{array}{c}3 \\
(m m o l)\end{array}$ & Product & Reaction time & $\mathrm{M}_{n}$ & $\mathrm{M}_{w}$ & $\mathrm{M}_{w} \mathrm{M}_{n}$ \\
\hline 1 & 180 & 188 & 0 & 0 & PBS & $3 \mathrm{~h}$ & 76500 & 142000 & 1.86 \\
\hline 2 & 181 & 181 & 5.5 & 0 & PBSODP3 & $6.5 \mathrm{~h}$ & 117700 & 203800 & 1.73 \\
\hline 3 & 181 & 181 & 5.4 & 1 & PBSODPAsp0.5 & $5 \mathrm{~h}$ & 69800 & 142900 & 2.05 \\
\hline 4 & 180 & 182 & 5.4 & 2 & PBSODP3Asp1 & $2 \mathrm{~h}$ & 47000 & 119000 & 2.52 \\
\hline 5 & 181 & 184 & 5.1 & 3.6 & PBSODP3Asp2 & $15 \min$ & 39600 & 296800 & 7.5 \\
\hline 6 & 180 & 177 & 9 & 0 & PBSODP5 & $7 \mathrm{~h}$ & 97100 & 187800 & 1.94 \\
\hline 7 & 180 & 177 & 9.1 & 1.8 & PBSODP5Asp1 & $3 \mathrm{~h}$ & 59000 & 132300 & 2.24 \\
\hline 8 & 180 & 177 & 9 & 3.6 & PBSODP5Asp2 & $45 \mathrm{~min}$ & 46300 & 294400 & 6.36 \\
\hline
\end{tabular}

Abbreviations: $M_{\mathrm{n}}$, number-average molecular weight; $M_{\mathrm{w}}$, weight-average molecular weight; $M_{\mathrm{w}} / M_{\mathrm{n}}$, molecular weight distribution; PBS, poly(butylene succinate); 1, succinic acid; 2, 1,4-butanediol; 3, L-aspartic acid; 5, 3-octadecyloxy-1,2-propanediol.

Table 8 The thermal and mechanical properties of PBS copolymers including 3-octadecyloxy-1,2-propanediol and aspartic acid

\begin{tabular}{|c|c|c|c|c|c|c|c|c|c|}
\hline Run & Product & $\begin{array}{l}\mathrm{T}_{g} \\
\left({ }^{\circ} \mathrm{C}\right)\end{array}$ & $\begin{array}{l}\mathrm{T}_{m} \\
(\mathrm{C})\end{array}$ & $\begin{array}{c}-\Delta \mathrm{H}_{m} \\
\left(m J m g^{-1}\right)\end{array}$ & $\begin{array}{l}\mathrm{T}_{d 2} \\
\left({ }^{\circ} \mathrm{C}\right)\end{array}$ & $\begin{array}{l}\text { Elastic } \\
(\mathrm{MPa})\end{array}$ & $\begin{array}{c}\text { Yield stress } \\
\text { (MPa) }\end{array}$ & $\begin{array}{c}\text { Break stress } \\
\text { (MPa) }\end{array}$ & $\begin{array}{c}\text { Break strain } \\
\text { (\%) }\end{array}$ \\
\hline 1 & PBS & -34.2 & 114.9 & 48.2 & 308.1 & 283.8 & 30.2 & 30.8 & 289 \\
\hline 2 & PBSODP3 & -26.7 & 111.5 & 88.3 & 325.7 & 156.8 & 23 & 52 & 898 \\
\hline 3 & PBSODPAsp0.5 & -28.7 & 111 & 86.3 & 325 & 133 & 22.9 & 38.4 & 630 \\
\hline 4 & PBSODP3Asp1 & -30.2 & 108.4 & 101 & 306 & 136.2 & 23.5 & 21.7 & 74 \\
\hline 5 & PBSODP3Asp2 & -26.9 & 109.8 & 110 & 297.7 & 156.3 & 28.9 & 28.8 & 19 \\
\hline 6 & PBSODP5 & -27.1 & 107.9 & 84.2 & 328.1 & 109.5 & 19.3 & 44.8 & 903 \\
\hline 7 & PBSODP5Asp1 & -25.9 & 109.2 & 94.7 & 315.1 & 115.4 & 19.6 & 27.4 & 496 \\
\hline 8 & PBSODP5Asp2 & -25.4 & 107.3 & 89.7 & 312.9 & 106.3 & 20.3 & 18.1 & 52 \\
\hline
\end{tabular}

Abbreviations: $\Delta H_{\mathrm{m}}$, heat of fusion; PBS, poly(butylene succinate); $T_{\mathrm{d} 2}, 2 \%$ thermal decomposition temperature; $T_{\mathrm{g}}$, glass transition temperature; $T_{\mathrm{m}}$, melting temperature.

explanation for the different behaviors between 3 and L-glutamic acid has not been found.

1 Taguchi, Y., Oishi, A., Fujita, K., Ikeda, K., Watanabe, K. \& Masuda, T. Preparation of poly(butylene succinate) containing monoacylglycerol unit. J. Oleo Sci. 49, 825-830 (2000).

2 Oishi, A., Nakano, H., Fujita, K., Yuasa, M. \& Taguchi, Y. Copolymerization of poly (butylene succinate) with 3-alkoxy-1,2-propanediols. Polym. J. 34, 742-747 (2002).

3 Zhang, M., Nakayama, K., Taguchi, Y., Oishi, Y. \& Masuda, T. 12th International Symposium on Fine Chemicals and Functional Polymers, Lanzhen, China, 2002, 8.

4 Oishi, A., Zhang, M., Nakayama, K., Masuda, T. \& Taguchi, Y. Synthesis of poly (butylene succinate) and poly(ethylene succinate) including diglycollate moiety. Polym. J. 38, 710-715 (2006).
5 Abe, H. \& Doi, Y. Novel biodegradable copolymers with a periodic sequence structure derived from succinate butan-1,4-diol, and butan-1,4-diamine. Macromol. Rapid Commun. 25, 1303-1308 (2004).

6 Shirahama, H., Aludin, M. S., Kawaguchi, Y., Migita, N. \& Yasuda, H. Chain extension and enzymatic degradation of aliphatic polyesters. J. Oleo Sci. 46, 1391-1397 (1997).

7 Takiyama, E. \& Hatano, Y. Jpn. Kokai Tokkyo Koho, JP1995304839 (1995).

8 Takiyama, E., Hokari, T. \& Ogura, T. Jpn. Kokai Tokkyo Koho, JP199339352 (1993).

9 Masuda, T. \& Cao, A. Jpn. Kokai Tokkyo Koho, JP2002356548 (2002).

10 Masuda, T. \& Cao, A. Jpn. Kokai Tokkyo Koho, JP2004315825 (2004).

11 Kasai, A. Jpn. Kokai Tokkyo Koho, JP1999130852 (1999).

12 Velmathi, S., Nagahata, R. \& Takeuchi, K. Extremely rapid synthesis of aliphatic polyesters by direct polycondensation of $1: 1$ mixtures of dicarboxylic acids and diols using microwaves. Polymer J. 39, 841-844 (2007).

13 Cao, A., Okamura, T., Ishiguro, C., Nakayama, K., Inoue, Y. \& Masuda, T. Studies on synthesis and physical characterization of biodegradable aliphatic poly(butylene succinate-co-caprolactone)s. Polymer 43, 671-679 (2002). 